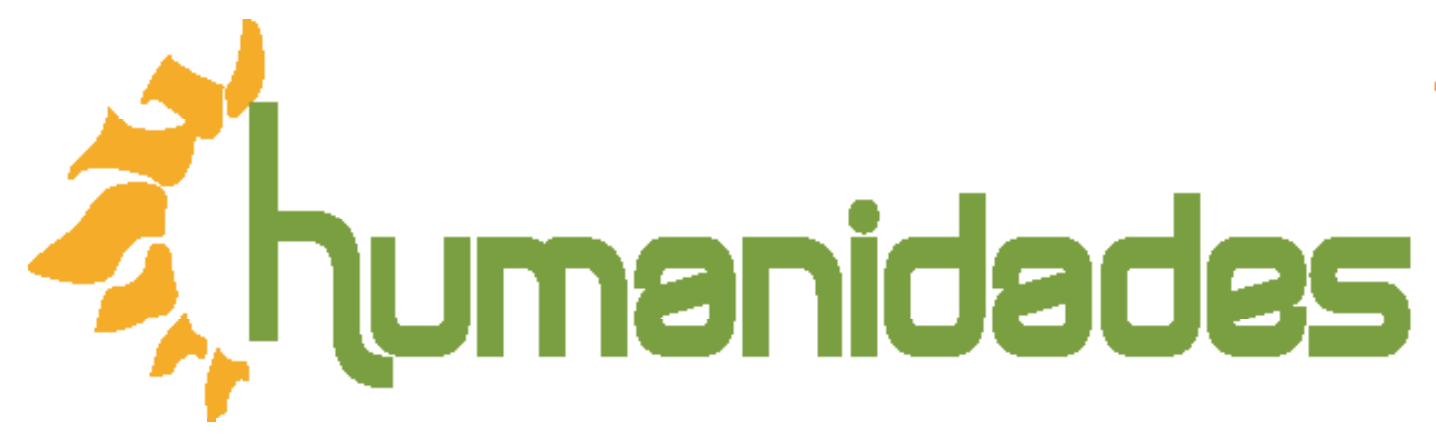

Revista de la Escuela de Estudios Generales, Universidad de Costa Rica

Julio-diciembre, $2019 \bullet$ Volumen 9, número 2 • EISSN 2215-3934•pp. 1-16

Recibido: 20-Enero-2019 Aceptado: 02-Abril-2019

\title{
Arte y conocimiento. La dimensión epistémica del proceso artístico en la contemporaneidad
}

DOI: https://doi.org/10.15517/h.v9i2.37126

\section{Paola Sabrina Belén}

Licenciada

Facultad de Bellas Artes. Universidad Nacional de La Plata. Instituto de Investigación en Producción y Enseñanza del Arte Argentino y Latinoamericano, Argentina

Correo electrónico: pbelen@fba.unlp.edu.ar

Todos los derechos reservados. Universidad de Costa Rica. Esta revista se encuentra licencida con Creative Commons. Reconocimiento-NoComercial-SinObraDerivada 3.0 Costa Rica. Correo electrónico: humanidades@ucr.ac.cr/ Sitio web: http: //revistas.ucr.ac.cr/index.php/humanidades 


\title{
Arte y conocimiento. La dimensión epistémica del proceso artístico en la contemporaneidad
}

\section{Resumen}

En el marco de las asignaturas Estética y Epistemología de las artes, este artículo se propone reflexionar sobre la enseñanza de estas disciplinas desde su concepción como prácticas educativas constructoras de saberes emancipadores. Se construye un fundamento teórico que entiende lo artístico como un proceso relacional y situacional con un modo específico de generar y sistematizar el conocimiento, posible de ser analizado en su experiencia receptiva-interpretativa y en su operatoria constructiva-creativa. Considerar la dimensión epistémica del arte requiere realizar una revisión crítica del marco conceptual en el que la modernidad construyó las nociones de la realidad.

\section{Art and Knowledge. The Epistemic Dimension of Artistic Process in Contemporaneity}

\begin{abstract}
In the framework of the Esthetic and Epistemology subjects of the arts, this article proposes to reflex about the lesson of these disciplines from their conception as constructive educational practices about emancipatory knowledges. A theoretical base is built that understands the artistic as a relational and situational process with a specific mode to generate and systemize knowledge, able to be analyzed in it's receptive-interpretative experience and in it's constructive-creative operation. Consider the epistemic dimension of art requires a critical revision of the conceptual framework in which modernity built reality notions.
\end{abstract}

Palabras clave:

Educación estética, filosofía del arte, arte contemporáneo

Keywords:

Aesthetic education, philosophy of art, contemporary art 


\section{Estética, Epistemología y saberes emancipadores}

Las ideas que se presentan en este artículo se enmarcan en el proyecto de investigación Fundamentos estéticos y su inclusión en los Planes de Estudio de las carreras universitarias de Artes, en el cual Paola Belén se desempeña como codirectora, con la dirección de la Lic. Silvia García. El proyecto se propone caracterizar y sistematizar ${ }^{1}$ los aspectos innovadores de la propuesta curricular de la asignatura Fundamentos estéticos para las carreras de Artes de la Facultad de Bellas Artes (FBA) en la Universidad Nacional de La Plata (UNLP)² desde una mirada interdisciplinaria que responda a la necesidad de una enseñanza innovadora de la Estética filosófica.

Generalmente, el/la alumno/a de la Facultad de Bellas Artes considera que estudiar arte implica apropiarse de diversas técnicas que posibilitan la producción de imágenes visuales, audiovisuales, sonoras, etc., por lo tanto, piensa que el desarrollo de la producción teórica no guarda relación y, en muchos casos, va en detrimento con su producción artística. Resulta entonces, imperioso, que el/ la estudiante pueda advertir que la separación de materias de corte teórico y los talleres obedecen tan solo a diferencias metodológicas, pero la praxis artística requiere tanto de la apropiación de técnicas como de herramientas conceptuales que le permitan pensar el campo de su producción artística. Es importante, además, que considere necesario situar su producción teniendo en cuenta los parámetros de nuestra cultura. De esta manera, contribuirá con la conformación tanto de su identidad como al desarrollo del pensamiento crítico, posibilitándole la discusión sobre los estereotipos que caracterizan la figura del artista ubicándolo en lugar casi sagrado, apartado de la sociedad.

Retomando lo anterior, el programa de la materia Fundamentos Estéticos está estructurado con base en teorías que problematizan el campo artístico, de esta manera, se articulan así, las diferentes áreas disciplinares en torno a un eje común que las atraviesa, con el objetivo de abordar el estudio desde distintos enfoques y contextualizarlo en el mundo contemporáneo, asumiendo, finalmente las múltiples dimensiones de lo artístico, lo político y lo social. 
Ahora bien, la asignatura se configura a partir de teorías que derivan de la necesidad de remitirse continuamente al despliegue real/práctico del mundo de las artes, en una doble vertiente: histórica y estructural. El aprendizaje de esta disciplina entonces, no queda en el plano de un saber especulativo, sino que teorías e imágenes se complementan mutuamente. Se promueve, de esta forma, el intercambio de experiencias desde distintas disciplinas artísticas que tienden a encontrar puntos comunes en el proceso de producción logrando una formación interdisciplinar que permite a los/las estudiantes posicionarse en el campo de la estética contemporánea.

Por tales motivos, esta experiencia, parte de lo que se caracteriza como una innovación desde los puntos de vista disciplinar y curricular, ya que encuentra sustento en el carácter procesual, histórico-social y constructivo de toda manifestación artística y ofrece una visión de la Estética desde una selección de ejes temático-conceptuales que se articulan a partir de textos e imágenes y no desde el reporte de una sucesión cronológica de autores relevantes en la historia de la disciplina. Se respalda así la construcción de un proceso intelectual, técnico y social que, inmerso en la complejidad de los procesos culturales actuales, propicia la validación del arte como conocimiento. Asimismo, se piensa la enseñanza de la Estética como una práctica educativa constructora de saberes emancipadores, con lo que se llevará a indagar también en los cruces entre la Estética y la Epistemología del arte.

En tal sentido, se recupera, además, la experiencia desarrollada en la FBA de la UNLP desde 2009, en el marco de la materia Epistemología de las artes ${ }^{3}$. Dicha asignatura construye un fundamento teórico que entiende lo artístico como un proceso relacional y situacional con un modo específico de generar y sistematizar el conocimiento, con la posibilidad de ser analizado tanto en su experiencia receptiva-interpretativa como en su operatoria constructiva-creativa. Aplica un especial énfasis en la operatoria constructiva-creativa, a partir de la denominada Investigación en Artes. 
Ahora bien, considerar la dimensión epistémica del arte requiere realizar una revisión crítica del marco conceptual en el que la modernidad construyó las nociones de arte, realidad, racionalidad, conocimiento, verdad, etc., y por ello, la materia reconstruye de modo estratégico un planteamiento historiográfico de autores inmersos en la filosofía occidental, que han desarrollado la reflexión teórica acerca de los aspectos epistemológicos del proceso artístico, desde el siglo XVIII hacia la contemporaneidad, época fundacional de una reconfiguración del concepto de arte.

Así, el tránsito por ambas asignaturas le proporciona al estudiante elementos conceptuales que le permiten reflexionar sobre su propia producción, superando de este modo la falsa dicotomía entre el hacer y el pensar. Se trata, entonces, de orientar a los estudiantes hacia la construcción de una visión situada que pueda concebir la producción artística como el resultado de un proceso puesto en juego desde el pensamiento y la acción. Entre los objetivos de esta educación está presente el concepto de emancipación, entendiendo este término como la liberación de cualquier tipo de dependencia. Esto es, la contribución de la educación a generar seres autónomos y plenos para operar por la obtención de sus derechos como seres humanos. Este último concepto, más que parte de una instrumentación didáctica, depende de una política educativa que seguramente se sustenta en un paradigma de acción política general.

En este sentido, la propuesta de Boaventura de Sousa Santos (2007) sobre lo que él denomina una "ecología de saberes"4 para desarrollar como paradigma educativo en todos los niveles de enseñanza, lo que contribuye a repensar y reconstruir un nuevo mapa educativo, especialmente el situado en países periféricos como son los de América Latina. En ese entorno es donde el proceso artístico como construcción epistémica puede ser uno de los pilares de la educación integral, junto con la denominada alfabetización científica y el pensamiento crítico. 


\section{Epistemología del arte y pensamiento complejo}

Valorar el papel del arte como agente concreto y modificador de la realidad, con la posibilidad de ser validado como campo de conocimiento genuino, permite dimensionar el proceso de construcción del conocimiento diverso y situacional, desde un paradigma complejo y relacional. Tomando como antecedentes la crisis del pensamiento positivista y el desarrollo de paradigmas científicos novedosos, a lo largo del siglo XX, se comenzaron a cuestionar los presupuestos naturalizados acerca del conocimiento. La modernidad pensó el conocimiento como el reflejo interno en el sujeto, de un mundo externo y objetivo. Esta forma dicotómica, que escinde al sujeto del objeto, implica pensar cada uno de los polos de manera absolutamente independiente del otro. En este sentido, como señala Najmanovich (2005) la forma canónica del conocimiento en Occidente puede esquematizarse de la siguiente manera:

1. Dicotómica.

2. A priori.

3. Monológica (lógica clásica).

4. Monodimensional.

5. Lineal.

6. Representacional.

7. Mecánica.

8. Determinista.

En ese marco, se conciben, además, algunos valores como universales a-priori:

1. Definición, unidad, uniformidad.

2. Exactitud y precisión, claridad y distinción.

3. Regularidad y estandarización.

4. Previsión, predicción, determinación. 
Esto conlleva a la ilusión totalizadora de un conocimiento universal -válido para todos los tiempos y lugares-, en el que el sujeto nunca es una presencia corporal, afectiva, socializada, interactiva y múltiple, y la búsqueda de la claridad y la distinción descarta todo lo borroso, difuso, irregular y ambiguo del mundo (Najmanovich, 2005, p. 28). Sin embargo, cuando esta concepción dualista comenzó a declinar se hizo evidente que constituye solo una perspectiva posible entre otras y no la forma natural del mundo (Rorty, 1989; Foucault, 1980; Deleuze y Guattari, 1976; Morin, 1981; Maturana y Varela, 1990). De este modo, vemos que los instrumentos conceptuales de la modernidad hoy resultan insuficientes para pensar nuestro mundo en acelerada mutación y, por ello, es necesario construir otros. Si, en lugar de la perspectiva moderna de la simplicidad, admitimos que la relación de conocimiento se inscribe dentro de una dinámica vincular -no dualista-, situada, dinámica e interactiva de un sujeto social en intercambio con un mundo en permanente transformación ${ }^{5}$, no es posible sostener la existencia de un mundo independiente, posible de ser descrito completa y objetivamente. En este nuevo marco, la emergencia, el devenir, el azar, lo multidimensional y relacional, lo polifónico y dialógico, la interacción de redes complejas, constituyen algunos de los rasgos centrales.

Tomando en cuenta lo anterior, no se trata, entonces, de una ampliación de la simplicidad ni de una complicación, sino que el pensamiento complejo implica "una transformación global de nuestra forma de experimentar el mundo, de coconstruirlo en las interacciones, de concebir y vivir nuestra participación en él, de producir, compartir y validar el conocimiento" (Najmanovich, 2005, p. 36). Esto supone, además, dar lugar a nuevas interrogantes y miradas sobre el mundo, de manera que resulte posible legitimar otras experiencias de conocimiento -configuradoras de mundo y productoras de sentido-, que habían sido desvalorizadas o negadas, insertándose allí la posibilidad de considerar la dimensión epistémica del arte. 


\section{Fundamentos teóricos del arte contemporáneo}

El análisis de tal estatuto epistémico requiere del redimensionamiento del concepto de arte, lo que además implica su abordaje interdisciplinar y procesual. El arte entonces no se ve como cosa o concepto definible y atemporal a partir de una acción de reducción y simplificación, sino que se interpreta aquí como proceso. Esto es un concepto relacional y situacional (Catalá, 2005; Bourriaud, 2006; Claramonte Arrufat, 2008), que se construye a partir de una red de sentido, en la cual intervienen tres elementos básicos: el denominado artista-hacedor-realizador-productor, la obra-objeto-acontecimiento (Con o sin dispositivo-plataforma que lo contenga) y el público-espectador-interactor-usuario. De esta interrelación, que es situacional y que forma parte de un valor social que le da sentido, emerge la situación de arte.

La variedad de materiales, soportes, contextos, temáticas, la disolución de los límites disciplinares, la irrupción del arte en contextos cotidianos, la transformación de objetos utilitarios en obras y el desarrollo de propuestas multimediales, son solo algunos de los aspectos en los que se advierte la ampliación de las fronteras de lo artístico en nuestra época. Asimismo, uno de los rasgos característicos de nuestras sociedades consiste en la estetización general de la vida. Las obras conviven con productos e imágenes que circulan en canales como el diseño, la publicidad y los medios de comunicación de masas, y en este marco se le plantea al arte una encrucijada. Este panorama, propicia sin duda una intensa problematización de la figura tradicional del artista, del estatuto de la obra artística y del rol del espectador. En nuestros días, el artista se enfrenta a la nueva situación desde una individualidad que ya no es la del héroe ni la del genio, sino solo la de una persona creativa que realiza proyectos. "Desaparece esa singularidad egregia del otro lado, del lado del artista-genio, como hombre... singularísimo y diferencial que viene -precisamente en su ejemplaridad distante del común- a epitomizar ese carácter discreto y singular, alejado de la tribu y la especie, del ser sujeto-individuo" (Brea, 2003, p. 30). 
El artista va progresivamente perdiendo su carácter sagrado, de sujeto iluminado y vanguardista para acercarse cada vez más al mismo nivel del público. Es "un inductor de situaciones intensificadas de encuentro y socialización de experiencia y un productor de mediaciones para su intercambio en la esfera pública” (Brea, 2003 , p. 128). Es ahora un "productor que fabrica herramientas que luego el público puede utilizar para desarrollar sus propias creaciones artísticas. El artista deja de ser creador para convertirse en médium" (Casacuberta, 2003, p. 34). En este contexto, la creación subjetiva es reemplazada por el concepto de heurística, es decir, la ciencia de la investigación, por tanto, del descubrimiento y la invención (Maldonado, 2005, p. 123). En definitiva, el nuevo artista es un proyector, un gestor, que no crea, sino que el proceso artístico contemporáneo parte de la heurística, es decir que busca resolver problemas.

La estimulación de experiencias cada vez más intensas en sujetos que reaccionan con todos sus sentidos y facultades, pasa a ser la meta de buena parte del arte contemporáneo. La obra, un proceso abierto, incompleto y dinámico, se concibe como una propuesta para la interacción e intervención múltiple, un proyecto que da posibilidades de acción y transformación a los sujetos, desde un nuevo rol que se concede al azar, la indeterminación, la inestabilidad ${ }^{6}$. La actividad del espectador puede entenderse no solo en el plano hermenéutico en el que se mueve la ontología estética de Gadamer (1991) o la estética de la recepción de Jauss e Iser, sino fundamentalmente en términos de una participación, entendida como intervención que afecta la producción, el hacer de la obra ${ }^{7}$. En conclusión, si la relación tradicional entre el espectador y la obra de arte se basaba en la existencia independiente de ambos y en el posicionamiento contemplativo del sujeto frente a objeto artístico ${ }^{8}$, el proceso artístico contemporáneo nos remite más bien a una ontología y a una epistemología compleja, relacional y dialógica. 


\section{Investigación en artes}

El esbozo de una propuesta racional, con dimensión epistémica del proceso artístico, implica la posibilidad de una replicación sistemática; pero al plantear una viabilidad emancipadora -y por tanto diferenciada de los planteos universalistas, homogéneos y totalitarios del proyecto moderno de la denominada civilización occidental-, tal propuesta no puede sustentarse en el modelo metodológico monista del positivismo, ni en ninguna de las variantes construidas desde el esquema epistémico anclado en la relación sujeto-objeto (citado ya anteriormente) ${ }^{9}$. Esto conlleva el hecho de tomar en cuenta las particularidades de esta construcción epistémica del proceso artístico y, desde una perspectiva compleja, relacional y situacional del mismo poder generar una sistematización que permita su replicación. Por tanto, se habla de investigación en las artes sólo cuando la práctica artística ofrece una contribución intencionada y original a aquello que ya conocemos y entendemos. Según Borgdhoff:

Se refiere a la investigación que no asume la separación de sujeto y objeto, y no contempla ninguna distancia entre el investigador y la práctica artística, ya que ésta es, en sí, un componente esencial tanto del proceso de investigación como de los resultados de la investigación. Este acercamiento está basado en la idea de que no existe ninguna separación fundamental entre teoría y práctica en las artes (2010, p. 10)

En síntesis, el arte implica objetos (la obra de arte), procesos (la producción de arte) y contextos (el mundo del arte: recepción, entorno cultural e histórico, etc.); pero, al mismo tiempo, es una práctica estética, por lo que aspectos como el gusto, la belleza y otras categorías estéticas pueden formar parte del tema de estudio. Además, es un ejercicio hermenéutico en tanto su sentido desemboca en múltiples interpretaciones que ponen en movimiento y alteran nuestra interpretación y visión del mundo (Borgdhoff, 2010, p. 17). 
La práctica artística puede entenderse como investigación si su propósito es aumentar nuestro conocimiento y comprensión, llevando a cabo una investigación original en y a través de objetos artísticos y procesos creativos en los que los investigadores procuren mostrar y articular el conocimiento encarnado en dichos trabajos y procesos artísticos específicos. A estas cualidades se les pueden sumar los aspectos integrales, complejos, relacionales y situacionales de los cuales se habló más arriba.

\section{Consideraciones finales}

Todo tiempo humano es un tiempo histórico y, como tal, sujeto a una interrelación entre la inteligencia humana, el entorno y sus semejantes, que determina cosmovisiones, Lebenswelt (mundo de la vida), Weltanschauung, (visión de mundo) para hacer una construcción modélica paradigmática y con ella operar en el mundo. El tiempo moderno dio prioridad en esta operación a la mediación de la razón como cualidad universal humana, estructurada de acuerdo con parámetros construidos a partir del mundo griego y el posterior devenir histórico europeo. Ese paradigma dominó el planeta y lo operó autoritariamente hasta la segunda mitad del siglo XX, cuando sus promesas de libertad, igualdad, fraternidad y certeza de verdad perdieron consistencia y mostró sus límites.

El tiempo histórico contemporáneo se presenta ante el marco de una complejidad, al cual la visión de mundo o el mundo de la vida moderno le resulta insuficiente, si no quiere resignarse a un modelo discriminador y excluyente de derechos hacia los seres humanos y de plazo limitado en el hábito extractivista y explotador del entorno. En este sentido, este tiempo contemporáneo requiere de una construcción epistémica que tenga en cuenta la diversidad, la complejidad, la relacionalidad y la situacionalidad, para operar en un marco inclusivo de los seres humanos y amigable con el entorno. El proceso artístico contemporáneo descrito aporta una dimensión epistémica que contempla estos requerimientos. La reconfiguración epistémica de lo artístico puede constituirse, entonces, en una herramienta apropiada para el análisis de los aspectos histórico-sociales que presenta la sociedad contemporánea. Por tanto, puede entendérselo como un saber emancipador, pero como todo tiempo humano, al establecerse como histórico es proactivo, esto es, a partir de acciones y decisiones sociales y culturales, no se instalará como paradigma por sí solo sino a partir de una acción política. 


\section{Notas}

1 De acuerdo con Torres y Cendales (2007, pp. 47-48), la sistematización como proceso de investigación recupera "los saberes y significados de la experiencia para potenciarla [...] produce, principalmente, nuevas lecturas, nuevos sentidos sobre la práctica. Si bien es cierto que se basa en la voz y la mirada de sus protagonistas, el resultado es una mirada más densa y profunda de la experiencia común de la cual puedan derivarse pistas para potenciarla o transformarla".

En tal sentido, a la luz de la reflexión crítica y colectiva que aquí se propone, "el conocimiento académico constituye un instrumento de reflexión cuando se integra, no como información fragmentaria sino como parte de los esquemas de pensamiento que activa una persona al interpretar la realidad concreta en la que vive y sobre la que actúa, organizando, sobre la base de ello, su propia experiencia. Y es, justamente, a través de la dimensión reflexiva, que el profesor deja de ser un mediador pasivo entre la teoría y la práctica, para convertirse en un mediador activo que desde la práctica reconstruye críticamente sus propias teorías" (Edelstein, 2002, pp. 479-480).

$21^{\circ}$ año de Prof. y Lic. en Historia de las Artes y $3^{\circ}$ año de Prof. y Lic. en Artes Plásticas, Diseño Multimedial, Artes Audiovisuales y Música Popular.

$34^{\circ}$ año de los Prof. y Lic. en Artes Plásticas, Diseño Multimedial y Artes Audiovisuales, y $3^{\circ}$ año del Prof. y Lic. en Historia de las artes.

4 “Consiste en la promoción de diálogos entre el saber científico y humanístico que la universidad produce y los saberes legos, populares, tradicionales, urbanos, campesinos, provincianos, de culturas no occidentales que circulan en la sociedad (...) La ecología de los saberes es un conjunto de prácticas que promueven una nueva convivencia activa de saberes con el supuesto de que todos ellos, incluido el saber científico, se pueden enriquecer en ese diálogo.” (De Sousa Santos, 2007, pp. 67-68). 
5 “... pensamos en, con, junto, contra el colectivo con el cual convivimos. Es el colectivo el que nos permite pensar y legitimar el conocimiento. Un colectivo que no incluye sólo a seres humanos, sino también tecnologías, espacios activos, que le dan forma, lo conforman y lo transforman.” (Najmanovich, 2005, p. 39).

${ }^{6}$ En la contemporaneidad, no son pocas las obras que lanzan al espectador la pregunta acerca de su propio estatuto artístico. En tal sentido el objeto ambiguo es el paradigma de la situación problemática del arte a la que debe enfrentarse en nuestros días el espectador. El arte no es una cosa ni está sujeto a una definición unívoca, en tal sentido Nelson Goodman (1990) advierte sobre las limitaciones y frustraciones que acarrean los intentos por responder a “¿Qué es el arte?” o “QQué objetos son (permanentemente) obras de arte?" y propone su desplazamiento a la pregunta “¿Cuándo hay arte?”.

${ }^{7}$ A estos cambios se suma que el público ha dejado de tener el carácter homogéneo que lo caracterizaba en el momento en que empieza a consolidarse en el siglo XVIII, presentando más bien en la actualidad un carácter intensamente plural y heterogéneo. La idea de "públicos", pone así en cuestión la homogeneidad y la búsqueda de la universalidad del gusto, propias del pensamiento ilustrado. Situación que además no resulta ajena a los diversos ámbitos o canales vinculados al universo artístico en nuestros días, esto es, mientras algunas obras circulan dentro de los espacios tradicionales (museo, galería, bienales o ferias) otras lo hacen fuera de los mismos, especialmente en el espacio urbano.

${ }^{8}$ La relación tradicional entre la obra de arte y el espectador remite a la concepción dualista o dicotómica de la forma canónica de conocimiento, caracterizada en la sección anterior.

9 Véase la sección "Epistemología del arte y pensamiento complejo". 


\section{Referencias}

Borgdorff, H. (2010). El debate sobre la investigación en las artes. Cai ron, (13), 25-46. Recuperado de https://www.ipd.gu.se/digi talAs sets/1322/1322698_el-debate-sobre-la-investigaci--n-en-las-artes.doc

Bourriaud, N. (2006). Estética relacional. Buenos Aires, Argentina: Adriana Hidalgo.

Brea, J. (2003). El tercer umbral - Estatuto de las prácticas artísticas en la era del capitalismo cultural. Murcia, España: CENDEAC.

Casacuberta, D. (2003). Creación colectiva - En internet el creador es el público. Barcelona, España: Gedisa.

Catala, J. (2005). La imagen compleja. La fenomenología de las imágenes en la era de la cultura visual. Barcelona, España: Universidad de Barcelona.

Claramonte, J. (22 de noviembre de 2008). Del arte de concepto al arte de contex to. Estética y Teoría del arte [Entrada de blog]. Recuperado de https:// jordiclaramonte.blogspot.com/search?q=concepto

Deleuze, G. y Guattari, F. (1976). Rizoma. Valencia, España: Pre-textos.

De Sousa Santos, B. (2007). La Universidad en el siglo XXI. Para una refor ma democrática y emancipatoria de la universidad. La Paz, Bolivia: CI DES-UMSA.

Dirección General de Cultura y Educación de la Provincia de Buenos Aires. (2016). Aportes para una educación artística desde la concepción de las artes integradas. Recuperado de http://www.abc.gov.ar/atistica/ sites/default/files/Aportes\%20para\%20una\%20Educaci\%C3\%B3n \%20 Art $\%$ C3\%ADstica_web.pdf 
Arte y conocimiento...

Edelstein, G. (2002). Problematizar las prácticas de la enseñanza. Perspectiva, 20(2), 467-482. Recuperado de https://periodicos.ufsc.br/index.php/ perspectiva/article/viewFile/10468/10008

Foucault, M. (1980). Las palabras y las cosas. México DF, México: Siglo XXI.

Gadamer, H. (1991). Verdad y método. Fundamentos de una hermenéutica filosófica. Salamanca, España: Sígueme.

Goodman, N. (1990). Maneras de hacer mundos. Madrid, España: Visor.

Maldonado, C. (2005). Heurística y producción de conocimiento nuevo en la perspectiva CTS. En I. Hernández García (Comp.), Estética, Ciencia y Tecnología - Creaciones electrónicas y numéricas (pp. 47-70). Bogotá, Colombia: Pontificia Universidad Javeriana.

Maturana, H. y Varela, F. (1990). El árbol del conocimiento. Santiago, Chile: Editorial Universitaria.

Morin, E. (1981). El Método. La naturaleza de la naturaleza. Madrid, España: Cátedra.

Najmanovich, D. (2005). Estética del pensamiento complejo. Andamios, 1(2), 19-42. Recuperado de: http://www.scielo.org.mx/pdf/anda/v1n2/v1n2a2. pdf

Rorty, R. (1989). La filosofía como espejo de la naturaleza. Madrid, España: Cátedra.

Torres Carrillo, A. y Cendales González, L. (2007). La sistematización como práctica investigativa y formativa. Pedagogía y Saberes, 1(26), 4150. Recuperado de http://revistas.pedagogica.edu.co/index.php/PYS/ article/view/6837 


\section{Fuentes de financiamiento}

Este artículo se inscribe en la investigación B358 "Fundamentos estéticos y su inclusión en los Planes de Estudio de las carreras universitarias de Artes", bajo la dirección de la Lic. Silvia García y la codirección de Paola Belén, financiada por el Programa de Incentivos a Docentes-Investigadores del Ministerio de Educación, Cultura, Ciencia y Tecnología (Argentina). Asimismo, ha contado con financiamiento del Subsidio para Viajes y/o Estadías de la Universidad Nacional de La Plata.

Vol. 9 (2), 2019 / EISSN: $2215-3934 \quad 16$ 